\title{
Mathematical Factor
}

National Cancer Institute

\section{Source}

National Cancer Institute. Mathematical Factor. NCI Thesaurus. Code C84380.

Any of the numbers (or symbols) that form a product when multiplied together. 